\title{
Recovery patterns and long term prognosis for axonal Guillain-Barré syndrome
}

\author{
A Hiraga, M Mori, K Ogawara, S Kojima, T Kanesaka, S Misawa, T Hattori, S Kuwabara
}

See Editorial Commentary, p 622

J Neurol Neurosurg Psychiatry 2005;76:719-722. doi: 10.1136/jnnp.2004.051136

See end of article for authors' affiliations

......................

Correspondence to: Dr Akiyuki Hiraga, Department of Neurology, Graduate School of Medicine, Chiba University, 1-8-1, Inohana, Chuo-ku, Chiba 2608670, Japan; hiragaa@ mail3.alpha-net.ne.jp

Received 2 August 2004 In revised form

29 September 2004

Accepted

29 September 2004

Background: Little is known about the long term prognosis for patients the severe acute motor axonal neuropathy (AMAN) form of Guillain-Barré syndrome (GBS), unlike those with acute inflammatory demyelinating neuropathy (AIDP).

Objective: To clarify the long term prognosis for patients with AMAN.

Methods: Clinical recovery and outcome in 97 consecutive GBS patients were reviewed.

Results: Electrodiagnostic criteria showed that 44 patients (45\%) had AMAN, 33 (34\%) had AIDP, and 20 $(21 \%)$ were unclassified. Most of the severely affected patients had received plasmapheresis or immunoglobulin therapy. Slow recovery (inability to walk independently at six months after onset) was found in six of the AMAN patients (14\%) and in two of the AIDP patients (6\%). Of the six AMAN patients, four could walk independently one year after the onset, and the other two could walk independently at 28 and 57 months after onset. Of the two AIDP patients, one could walk at nine months after the onset while the other died of pneumonia seven months after onset.

Conclusions: AMAN electrodiagnosis is not always a marker of poor recovery. Almost all the severe AMAN patients who had slow recoveries over the first six months could eventually walk independently, although some required several years.

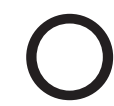
$\mathrm{n}$ the basis of pathological and electrophysiological observations, Guillain-Barré syndrome (GBS) has been regarded as a type of demyelinating neuropathy. In 1986, Feasby et al identified an axonal type of GBS coupled with poor recovery characterised by severe Wallerian-like degeneration in the peripheral nerves at necropsy. ${ }^{1}$ In the 1990s, a pure motor axonal form of GBS, designated acute motor axonal neuropathy (AMAN), was recognised in northern China $^{2-4}$ and later reported in other countries. ${ }^{5-12}$ Based on the electrophysiological and pathological findings, GBS is currently divided into demyelinating and axonal forms: acute inflammatory demyelinating polyneuropathy (AIDP) and AMAN. ${ }^{1-12}$ Axonal GBS is usually characterised by electrophysiological and pathological evidence of axonal degeneration of the motor nerves together with functional conduction failure or other pathophysiology, and a possible association with anti-ganglioside antibodies, Campylobacter jejuni infection, or both. ${ }^{10}$ Electrophysiological evidence of axonal degeneration is thought to be an indicator of poor prognosis, ${ }^{8}{ }^{13-18}$ but AMAN patients often show rapid recovery. ${ }^{19-21}$ Moreover, little is known about the long term outcome in these patients. We investigated differences in recovery patterns of AIDP and AMAN patients, and clarified the long term prognosis for severely disabled AMAN patients.

\section{METHODS}

\section{Patients}

We studied a series of 97 consecutive GBS patients seen at Chiba University Hospital or Matsudo Municipal Hospital between 1992 and 2002. All fulfilled the clinical criteria for GBS. ${ }^{22}$ Disabilities were evaluated on the Hughes functional grading scale (grade 6, dead; grade 5, requires assisted respiration; grade 4, bed bound; grade 3, able to walk $5 \mathrm{~m}$ with aid; grade 2, ambulates independently; grade 1, minimal signs and symptoms, able to run; grade 0, normal). Patients were followed for more than six months from neurological onset. Rapid recovery was defined as an improvement by two or more Hughes grades within four weeks after onset, and slow recovery as the inability to walk independently (grade 3 or more) six months after neurological onset.

\section{Electrophysiology}

Nerve conduction studies were undertaken using conventional procedures. Motor conduction studies were made on the median, ulnar, tibial, and peroneal nerves, and sensory conduction studies on the median, ulnar, and sural nerves. Patients were classified as having AMAN or AIDP on the basis of the electrodiagnostic criteria of Ho et al. ${ }^{4}$ When patients had one of the following findings in two or more nerves during the first two weeks of illness, they were classified as having AIDP:

- conduction velocity $<90 \%$ of lower limit of normal if amplitude is $>50 \%$ of the lower limit of normal; $<85 \%$ if amplitude is $<50 \%$ of lower limit of normal;

- distal latency $>110 \%$ of upper limit of normal if amplitude is normal; $>120 \%$ of upper limit of normal, if the amplitude is less than lower limit of normal;

- evidence of unequivocal temporal dispersion;

- F response latency $>120 \%$ of normal.

When patients had no evidence of demyelination as defined for AIDP, and had a decrease in CMAP to $<80 \%$ of lower limit of normal in two or more nerves, they were classified as having AMAN.

\section{Statistical analysis}

Differences in proportions were tested with the $\chi^{2}$ or Fisher's exact test, and differences in medians with the MannWhitney $U$ test. A probability (p) value of $<0.05$ was considered significant. Kaplan-Meier curves were used to analyse the time taken to reach Hughes grade 2 (independent locomotion).

Abbreviations: AIDP, acute inflammatory demyelinating polyneuropathy; AMAN, acute motor axonal neuropathy; GBS, Guillain-Barré syndrome 


\begin{tabular}{|c|c|c|c|}
\hline \multirow[b]{2}{*}{ Electrodiagnosis } & \multirow{2}{*}{$\frac{\text { AMAN }}{(n=44)}$} & \multirow{2}{*}{$\frac{\text { AIDP }}{(n=33)}$} & \multirow[b]{2}{*}{$\mathrm{p}$ Value } \\
\hline & & & \\
\hline Age (y) (mean (SD)) & $37(18)$ & $44(18)$ & NS \\
\hline Sex (M:F) (n) & $26: 18$ & $20: 13$ & NS \\
\hline \multicolumn{4}{|l|}{$\begin{array}{l}\text { Antecedent infection } \\
\text { (n (\%)) }\end{array}$} \\
\hline Enteritis & $23(52 \%)$ & $1(3 \%)$ & $<0.001$ \\
\hline URTI & $16(36 \%)$ & $20(61 \%)$ & 0.03 \\
\hline \multicolumn{4}{|l|}{$\begin{array}{l}\text { Hughes grade at nadir } \\
\text { (n (\%)) }\end{array}$} \\
\hline$i$ & $2(5 \%)$ & $2(6 \%)$ & \\
\hline 2 & $16(36 \%)$ & $9(27 \%)$ & \\
\hline 3 & $4(9 \%)$ & $7(21 \%)$ & \\
\hline 4 & $18(41 \%)$ & $5(15 \%)$ & \\
\hline 5 & $4(9 \%)$ & $9(27 \%)$ & \\
\hline 6 & $0(0 \%)$ & $1(3 \%)$ & \\
\hline $\begin{array}{l}\text { Median/mean } \\
\text { (range) }\end{array}$ & $\begin{array}{l}3.5 / 3.1 \\
(1 \text { to } 5)\end{array}$ & $\begin{array}{l}3.0 / 3.4 \\
(1 \text { to } 6)\end{array}$ & NS \\
\hline \multicolumn{4}{|l|}{ Treatment (n (\%)) } \\
\hline IVIG & $13(30 \%)$ & $11(33 \%)$ & NS \\
\hline Plasmapheresis & $21(48 \%)$ & $14(42 \%)$ & NS \\
\hline None & $10(23 \%)$ & $8(24 \%)$ & NS \\
\hline
\end{tabular}

AIDP, acute inflammatory demyelinating polyneuropathy; AMAN, acute motor axonal neuropathy; IVIG, intravenous immunoglobulin; URTI, upper respiratory tract infection.

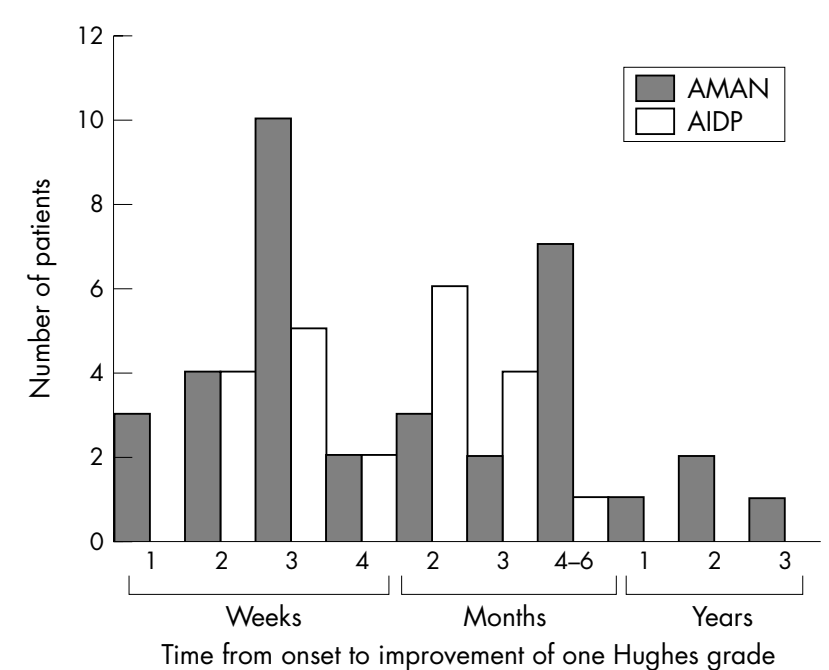

Figure 1 Histograms showing periods until an improvement of one Hughes grade from onset. The acute motor axonal neuropathy group (AMAN) (black bars; $n=35$ ) had two subgroups of patients who improved by one grade within four weeks or over a period of months. The acute inflammatory demyelinating polyneuropathy group (AIDP) had a relatively uniform pattern (white bars; $n=22$ ).

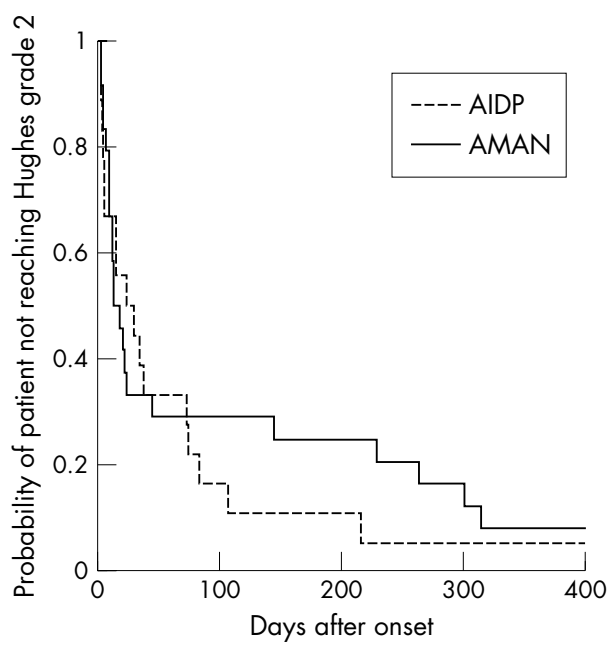

Figure 2 Kaplan-Meier curves showing the probability that patients would not recover independent locomotion (Hughes grade 2). AIDP, acute inflammatory demyelinating polyneuropathy; AMAN, acute motor axonal neuropathy.

\section{Patients unable to walk six months after onset}

Of all the GBS patients, eight (two AIDP and six AMAN) were unable to walk (Hughes grade 3 or more) six months after onset. The clinical profiles of these eight patients are shown in table 3. All had received immune treatment. Low distal CMAP (less than $20 \%$ of the lower limit of normal) associated with a long possibly incomplete recovery, as reported previously, ${ }^{18}$ was present in six of the eight patients. Figure 3 shows the milestones in the recovery of each patient. Of the six AMAN patients, four could walk independently one year after neurological onset, one could walk independently at 28 months after the onset, and the other could walk independently at 57 months after onset. Of the two AIDP patients, one could walk independently nine months after the neurological onset, but the other died of respiratory failure and infection at seven months after the onset. No death occurred in the AMAN group. 
Table 2 Recovery measures and treatment methods

\begin{tabular}{|c|c|c|c|c|c|c|c|c|}
\hline \multirow[b]{3}{*}{ Variable } & \multicolumn{4}{|l|}{ AMAN } & \multicolumn{4}{|l|}{ AIDP } \\
\hline & \multicolumn{4}{|c|}{ Treatment (No of patients) } & \multicolumn{3}{|c|}{ Treatment (No of patients) } & \multirow[b]{2}{*}{ Total $(n=33)$} \\
\hline & IVIG $(n=13)$ & $\operatorname{PP}(n=21)$ & None $(n=10)$ & Total $(n=44)$ & IVIG $(n=11)$ & $\operatorname{PP}(n=14)$ & None $(n=8)$ & \\
\hline \multirow[t]{2}{*}{$\begin{array}{l}\text { Improvement by two or more } \\
\text { Hughes grades during the first } \\
\text { four weeks } \\
\text { Hughes grade } 3 \text { or more six } \\
\text { months after onset }\end{array}$} & $4(9 \%)$ & $8(18 \%)$ & $0(0 \%)$ & 12 (27\%) & $4(12 \%)$ & $2(6 \%)$ & $0(0 \%)$ & $6(18 \%)$ \\
\hline & $2(5 \%)$ & $4(9 \%)$ & $0(0 \%)$ & $6(14 \%)$ & $2(6 \%)$ & $0(0 \%)$ & $0(0 \%)$ & $2(6 \%)$ \\
\hline
\end{tabular}

\section{DISCUSSION}

Our results confirm that two patterns of clinical recovery are found in AMAN patients, in contrast to a relatively uniform recovery in AIDP patients; they showed that the long term prognosis of patients with severe AMAN was quite good, with most of the severely disabled patients being able to walk independently within a few years.

Necropsy studies of AMAN patients have detected extensive Wallerian-like degeneration in the ventral roots. ${ }^{3}$ Although some AMAN patients experience slow, incomplete recovery, many recover well. ${ }^{9-21}$ In a report on the patterns of recovery of 32 AMAN and eight AIDP patients in northern China, ${ }^{19}$ some of the AMAN group had rapid clinical recoveries, and the recovery times of AIDP and AMAN patients were similar. In our previous study of 41 GBS cases, the anti-GMl positive patients - most of whom had AMANhad two patterns of clinical recovery: rapid and prolonged. AMAN patients in our present study had a two phase recovery pattern similar to that of the former anti-GMl positive patients. This good potential for recovery from AMAN suggests that extensive axonal degeneration is not always the underlying pathophysiology. The rapid recovery of AMAN patients may be explained by early resolution of physiological conduction failure at the nodes of Ranvier in the motor fibres ${ }^{192324}$ or by collateral sprouting of surviving axons, as proposed previously. ${ }^{20}$

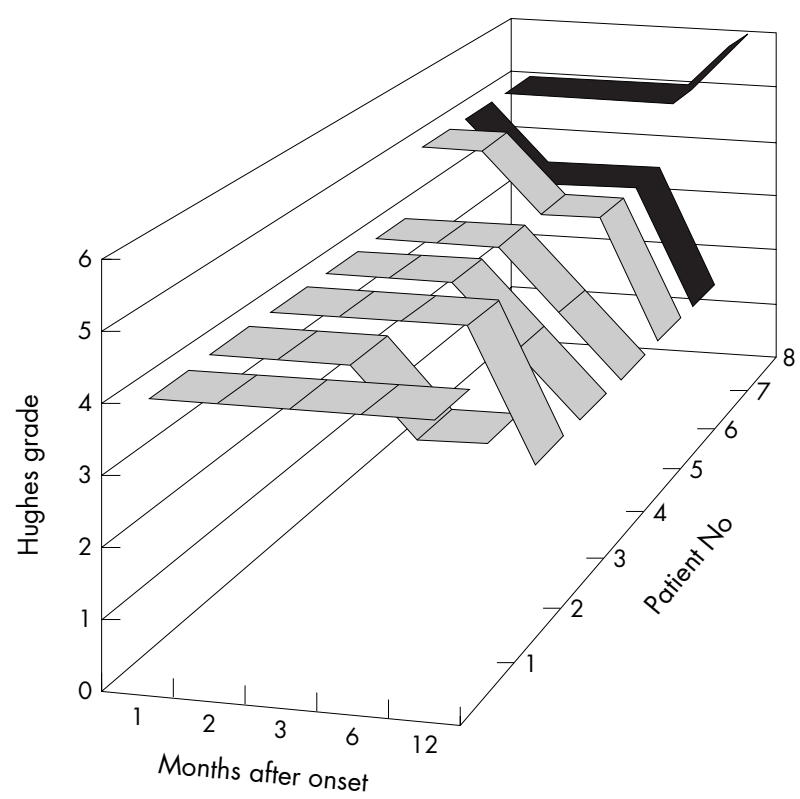

Figure 3 Milestones of recovery for Guillain-Barré syndrome patients unable to walk independently at six months after onset. Grey bars, acute motor axonal neuropathy (patients 1-6); black bars, acute inflammatory demyelinating polyneuropathy (patients 7 and 8 ).
The functional outcome of GBS in large series has been well documented. ${ }^{11}{ }^{14} 16^{25-27}$ In the MGH retrospective series, $6 \%$ needed canes, crutches, or braces to walk at six to nine months, 3\% remained wheelchair bound at two to three years, and 5\% had died at 15 to 210 days after disease onset. ${ }^{25}$ In south-east England in 1983-1984, 8\% of 87 surviving GBS patients still had a disability grade of 3 or 4 one year after onset. ${ }^{14}$ At that time, $13 \%$ of the GBS patients in the study had died, ${ }^{14}$ and $20 \%$ of 79 patients in a $1993-1994$ survey. ${ }^{26}$ In a recent large prospective Italian study, 15\% of 108 surviving GBS patients had a disability grade of 3 or more two years after onset. ${ }^{11}$ In a Dutch study, $24 \%$ of 147 GBS patients had a disability grade of 2 or more at six months, ${ }^{16}$ and $11 \%$ could not walk independently $2.5-6.5$ years after onset. ${ }^{27}$ Immune treatment is strongly associated with the prognosis for GBS patients; thus it is hard to compare results of our present study with studies done before the introduction of intravenous immunoglobulin or plasmapheresis.

The frequency of AMAN varies according to country, from only $7 \%$ of GBS patients studied in England ${ }^{28}$ and 3\% in a multicentre study done in 11 Western countries ${ }^{29}$ to $65 \%$ in a study in northern China. ${ }^{4}$ The low percentages of patients with AMAN in Western countries may affect study results. Previous studies of the long term prognosis for GBS patients in Western countries focused on AIDP, and little is known about the long term outcome for patients with AMAN. Of 32 AMAN and eight AIDP patients in northern China, ${ }^{19}$ more than $90 \%$ of the AMAN patients and all the AIDP patients could walk five metres with a walker or support. The Chinese AMAN patients, however, were markedly younger (median age 10 years) than the AIDP patients (median age 42 years). A comparison of the prognosis for AMAN and AIDP patients is therefore difficult. In the multicentre study of 369 GBS patients in 11 Western countries, ${ }^{29}$ axonal GBS accounted for $3 \%$ ( 10 patients); $10 \%$ of those with the axonal form and $17 \%$ with the demyelinating form could not walk or were dead 48 weeks after onset. The numbers of patients unable to walk and those who died did not differ significantly for the axonal and demyelinating forms. AIDP can be accompanied by secondary axonal degeneration in severe cases, and AMAN could be associated with functional conduction block as well as axonal loss. ${ }^{24}$ These might be the reasons why the long term prognosis of AMAN and AIDP is almost the same.

In our study, $8 \%$ of the 97 patients with GBS ( six AMAN and two AIDP) could not walk independently at six months after onset. In the AMAN group, four of the six could walk independently one year after onset, one could walk independently 28 months after onset, and the remaining patient could walk 57 months after onset. Generally, it is believed that no further recovery can be expected two to three years after GBS, ${ }^{30}$ but follow up has mainly been limited to six months or one year in most previous studies, which may be the reason for the overly pessimistic outlook for long term recovery from severe GBS. ${ }^{31}$ In our study, two AMAN patients who had slow recoveries could walk independently 28 and 57 
Table 3 Patients unable to walk independently at six months after onset

\begin{tabular}{|c|c|c|c|c|c|c|c|c|c|}
\hline Patient No & Age (y) & Sex & Electrodiagnosis & $\begin{array}{l}\text { Antecedent } \\
\text { infection }\end{array}$ & Treatment & $\begin{array}{l}\text { Hughes grade } \\
\text { at nadir }\end{array}$ & $\begin{array}{l}\text { Days to } \\
\text { nadir }\end{array}$ & $\begin{array}{l}\text { Time (months) to } \\
\text { reach independent } \\
\text { locomotion }\end{array}$ & Low CMAPs* \\
\hline 1 & 43 & $\mathrm{~F}$ & AMAN & Enteritis & $\mathrm{PP}$ & 4 & 15 & 57 & Yes \\
\hline 2 & 30 & $M$ & AMAN & Enteritis & PP & 5 & 6 & 28 & Yes \\
\hline 3 & 44 & $M$ & AMAN & Enteritis & PP & 4 & 1 & 8 & No \\
\hline 4 & 17 & M & AMAN & Enteritis & PP & 4 & 7 & 11 & Yes \\
\hline 5 & 17 & M & AMAN & Enteritis & IVIG & 5 & 7 & 9 & Yes \\
\hline 6 & 65 & $\mathrm{~F}$ & AMAN & URTI & IVIG & 5 & 3 & 10 & Yes \\
\hline 7 & 53 & $\mathrm{~F}$ & AIDP & URTI & IVIG & 5 & 9 & 9 & Yes \\
\hline 8 & 75 & $\mathrm{~F}$ & AIDP & Others & IVIG & 6 & $30+$ & - & No \\
\hline
\end{tabular}

*Low distal CMAPs (less than $20 \%$ of the lower limit of normal) in at least two nerves.

tHughes grade 5 considered to be the peak of illness 30 days after onset; died (Hughes grade 6) seven months after onset.

AIDP, acute inflammatory demyelinating polyneuropathy; AMAN, acute motor axonal neuropathy; CMAP, compound motor action potential; F, female; IVIG,

intravenous immunoglobulin; $M$, male; PP, plasmapheresis; URTI, upper respiratory tract infection.

months after onset. In addition, in the Dutch study, $21 \%$ of the GBS patients continued to improve after 2.5 to 6.5 years. ${ }^{27}$ The mechanism of improvement in patients with severe GBS several years after onset is not clear, but axonal regeneration along the course of the nerve may account for it.

\section{Conclusions}

Most of the severely disabled AMAN patients who are unable to walk six months after onset, may still show improvement over a period of years and may ultimately be able to walk independently. Neurologists should conduct long term follow up studies of severe AMAN patients and recommend long term rehabilitation.

\section{Authors' affiliations}

A Hiraga, M Mori, K Ogawara, T Kanesaka, S Misawa, T Hattori, S Kuwabara, Department of Neurology, Chiba University Graduate School of Medicine, Chiba, Japan

S Kojima, Department of Neurology, Matsudo Municipal Hospital, Matsudo, Japan

Competing interests: none declared

\section{REFERENCES}

1 Feasby TE, Gilbert JJ, Brown WF, et al. An acute axonal form of Guillain-Barre polyneuropathy. Brain 1986;109:1115-26.

2 McKhann GM, Cornblath DR, Griffin JW, et al. Acute motor axonal neuropathy: a frequent cause of acute flaccid paralysis in China. Ann Neurol 1993;33:333-42.

3 Griffin JW, Li CY, Ho TW, et al. Guillain-Barre syndrome in northern China: the spectrum of neuropathological changes in clinically defined cases. Brain 1995: 118:577-95.

4 Ho TW, Mishu B, Li CY, et al. Guillain-Barre syndrome in northern China: relationship to Campylobacter jejuni infection and anti-glycolipid antibodies. Brain 1995; 118:597-605

5 Visser LH, van der Meche FGA, van Doorn PA, et al. Guillain-Barre syndrome without sensory loss (acute motor neuropathy): a subgroup with specific clinical, electrodiagnostic and laboratory features. Brain 1995;118:841-7.

6 Rees JH, Soudain SE, Gregson NA, et al. Campylobacter jejuni infection and Guillain-Barre syndrome. N Engl J Med 1995;333:1374-9.

7 Lyu R-K, Tang L-M, Cheng S-Y, et al. Guillain-Barre syndrome in Taiwan: a clinical study of 167 patients. I Neurol Neurosurg Psychiatry 1997:63:494-500

8 Emilia-Romagna Study Group. A prospective study on the incidence and prognosis of Guillain-Barre syndrome in Emilia-Romagna region, Italy (19921993). Neurology 1997;48:214-21.

9 Kuwabara S, Asahina $M$, Koga $M$, et al. Two patterns of clinical recovery in Guillain-Barre syndrome with $\lg G$ anti-GM1 antibody. Neurology 1998;51:1656-60.

10 Ogawara K, Kuwabara S, Mori M, et al. Axonal Guillain-Barre syndrome: relation to anti-ganglioside antibodies and Campylobacter jejuni infection in Japan. Ann Neurol 2000;48:624-31.
11 Chio A, Cocito D, Leone $M$, et al. Guillain-Barre syndrome: a prospective, population-based incidence and outcome survey. Neurology 2003;60: 11 146-50

12 Dourado ME, Duarte RC, Ferreira LC, et al. Anti-ganglioside antibodies and clinical outcome of patients with Guillain-Barre syndrome in northeast Brazil. Acta Neurol Scand 2003;108:102-8.

13 McKhann GM, Griffin JW, Cornblath DR, et al. Plasmapheresis and GuillainBarre syndrome: analysis of prognostic factors and the effect of plasmapheresis. Ann Neurol 1988;23:347-53.

14 Winer JB, Hughes RAC, Osmond C. A prospective study of acute idiopathic neuropathy. I. Clinical features and their prognostic value. J Neurol Neurosurg Psychiatry 1988;51:605-12.

15 The Italian Guillain-Barré Study Group. The prognosis and main prognostic indicators of Guillain-Barre syndrome. A multicentre prospective study of 297 patients. Brain 1996;119:2053-61

16 Visser LH, Schmitz PIM, Meulstee J, et al. Prognostic factors of Guillain-Barre syndrome after intravenous immunoglobulin or plasma exchange. Neurology 1999;53:598-604.

17 Hadden RDM, Karch $\mathrm{H}$, Hartung $\mathrm{H}-\mathrm{P}$, et al. Preceding infections, immune factors, and outcome in Guillain-Barre syndrome. Neurology 2001:56:758-65.

18 Cornblath DR, Mellits ED, Griffin JW, et al. Motor conduction studies in Guillain-Barré syndrome: description and prognostic value. Ann Neurol 1988;23:354-9.

19 Ho TW, Li CY, Cornblath DR, et al. Patterns of recovery in the Guillain-Barre syndromes. Neurology 1997;48:695-700.

20 Kuwabara S, Ogawara K, Mizobuchi K, et al. Mechanisms of early and late recovery in acute motor axonal neuropathy. Muscle Nerve 2001;24:288-91.

21 Kuwabara S, Mori M, Ogawara K, et al. Indicators of rapid clinical recovery in Guillain-Barre syndrome. I Neurol Neurosurg Psychiatry $2001 ; 70: 560-2$.

22 Asbury AK, Cornblath DR. Assessment of current diagnostic criteria for Guillain-Barre syndrome. Ann Neurol 1990;27(suppl):S21-4.

23 Ho TW, Hsieh S-T, Nachamkin I, et al. Motor nerve terminal degeneration provides a potential mechanism for rapid recovery in acute motor axonal neuropathy after Campylobacter infection. Neurology 1997;48:717-24.

24 Kuwabara S, Yuki N, Koga $M$, et al. lgG anti-GMl antibody is associated with reversible conduction failure and axonal degeneration in Guillain-Barre syndrome. Ann Neurol 1998;44:202-8.

25 Ropper AH, Wijdicks EFM, Truax BT. Guillain-Barre syndrome. Philadelphia: FA Davis, 1991.

26 Rees JH, Thompson RD, Smeeton NC, et al. Epidemiological study of GuillainBarre syndrome in south east England. I Neurol Neurosurg Psychiatry 1998;64:74-7.

27 Bernsen RAJAM, de Jager AEJ, Schmitz PIM, et al. Long-term impact on work and private life after Guillain-Barre syndrome. J Neurol Sci 2002;201:13-17.

28 Ree JH, Gregson NA, Hughes RAC. Anti-ganglioside $\mathrm{GM}_{1}$ antibodies in Guillain-Barre syndrome and their relationship to Campylobacter jejuni infection. Ann Neurol 1995:38:809-16.

29 Hadden RDM, Cornblath DR, Hughes RAC, et al. Electrophysiological classification of Guillain-Barre syndrome: clinical associations and outcome. Ann Neurol 1998;44:780-8.

30 Ropper AH. Severe acute Guillain-Barre syndrome. Neurology 1986;36:429-32.

31 Fletcher DD, Lawn ND, Wolter TD, et al. Long-term outcome in patients with Guillain-Barre syndrome requiring mechanical ventilation. Neurology 2000;54:2311-15 